\title{
“The more things change...": The challenges ahead
}

\author{
Daniel J. Licht, MD
}

\footnotetext{
From the June and Steve Wolfson Laboratory for Clinical and Biomedical Optics, The Children's Hospital of Philadelphia, Philadelphia, Pa.

Disclosures: Dr Licht is supported by the National Institute of Neurological Disorders and Stroke (Grants R01 NS72338 and R01 NS060653), the Eunice Kennedy Shriver National Institute of Child Health and Human Development (Grant U01 HD087180-01), and the June and Steve Wolfson Family Foundation. He has nothing to disclose with regard to commercial support.

Received for publication April 17, 2017; accepted for publication April 21, 2017; available ahead of print June 13, 2017.

Address for reprints: Daniel J. Licht, MD, June and Steve Wolfson Laboratory for Clinical and Biomedical Optics, Colket Translational Research Building, 10th Floor, Room 100303501, Civic Center Blvd, Philadelphia, PA 19104 (E-mail: licht@email.chop.edu).

J Thorac Cardiovasc Surg 2017;154:1026-7

0022-5223/\$36.00

Copyright (C) 2017 by The American Association for Thoracic Surgery

http://dx.doi.org/10.1016/j.jtcvs.2017.04.066
}

We have known for some time now that the most common long-term morbidities of newborn heart surgery are related not to the heart, but instead to the cognitive challenges experienced by this population. The first and most comprehensive study to describe the neurodevelopmental challenges was the Boston Circulatory Arrest Trial (BCAT), which followed participants from birth to the recently reported 16-year outcomes. ${ }^{1}$ The BCAT results show that compared to national normative data, teens with congenital heart defects (CHD) were twice as likely to have a full-scale IQ $<1$ SD from the mean (31\% vs $16 \%$ in normative data) and 3 times as likely to have a full scale IQ $<2$ SD from the mean ( $6 \%$ vs $2 \%$ ).

In this issue of the Journal, Dr Kalfa and colleagues ${ }^{2}$ report long-term cognitive outcomes in young adults (average age, 23 years) from Ile-de-France who had undergone the arterial switch operation as newborns. Here, as in the BCAT, the proportion of survivors with test scores $<1$ SD was double and that of survivors with test scores $<2$ SD was triple of the expected values based on normative data. The patients in this study are only marginally older (7 years) than those in the BCAT, but the findings provide independent confirmation of the results in a cohort operated on in a different country. This is reminiscent of Gaynor and colleagues' study of pooled 1-year Bayley Scales of Infant Development (BSID) data from 22 institutions, ${ }^{3}$ which reported strikingly similar short-term neurodevelopmental outcomes across institutions, which were not significantly improved over the 2 decades of the study.

So where does that leave us? If scores are not different across centers or surgical strategy, and have not improved over time, does that mean we are helpless to improve neurodevelopmental outcomes in this population? The lack of change across time and place of surgery suggest that prenatal and presurgical factors weigh heavily on outcomes and can help us be more directed in our quest for interventions. Two very plausible lines of attack exist and are currently being pursued: maternal/fetal interventions and the prevention of white matter injury.

\section{References}

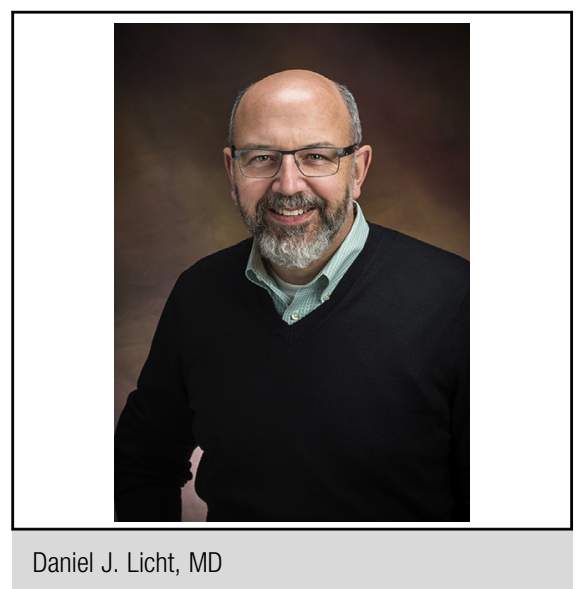

Central Message

Cognitive and performance outcomes after newborn heart surgery seem to be the same regardless of the surgical era or country in which they are measured.

See Article page 1028 .

Maternal/fetal intervention studies are a brave new path for improving outcomes, and some studies are already underway, including studies of maternal hyperoxia and maternal supplemental progesterone, and others are in the planning stage. There are major roadblocks ahead, given that standard assessments of drug bioavailability and safety are inadequate or not feasible in the fetus. In some states, laws that were enacted to protect the fetus now broadly prohibit/inhibit fetal research. Furthermore, institutional review boards do not have precedent and may feel poorly prepared to adjudicate regarding the safety of fetal drug trials.

Currently, all research on white matter injury in severe $\mathrm{CHD}^{4-6}$ has pointed to maturational vulnerability ${ }^{7,8}$ as a leading risk factor. However, there is recent evidence implicating the timing of surgery as a major modifiable risk factor. ${ }^{9,10}$ Dr Kalfa and colleagues ${ }^{2}$ give us hope, given their identification of time to surgery as a significant risk factor for poor long-term outcomes in their study.

In summary, for this challenging but deserving patient population, poor long-term neurodevelopmental outcomes remain heartbreaking; however, there are glimmers of hope that need to be aggressively pursued.

1. Bellinger DC, Wypij D, Rivkin MJ, DeMaso DR, Robertson RL Jr, DunbarMasterson C, et al. Adolescents with d-transposition of the great arteries corrected with the arterial switch procedure: neuropsychological assessment and structural brain imaging. Circulation. 2011;124:1361-9. 
2. Kalfa D, Kasmi L, Geronikola N, Calderon J, Lambert V, Belli E, et al. Cognitive outcomes and health-related quality of life in adults two decades after the arterial switch operation for transposition of the great arteries. J Thorac Cardiovasc Surg. 2017; 154:1028-35.

3. Gaynor JW, Stopp C, Wypij D, Andropoulos DB, Atallah J, Atz AM, et al. Neurodevelopmental outcomes after cardiac surgery in infancy. Pediatrics. 2015;135:816-25.

4. Licht DJ, Shera DM, Clancy RR, Wernovsky G, Montenegro LM, Nicolson SC, et al. Brain maturation is delayed in infants with complex congenital heart defects. J Thorac Cardiovasc Surg. 2009;137:529-36.

5. Miller SP, McQuillen PS, Hamrick S, Xu D, Glidden DV, Charlton N, et al. Abnormal brain development in newborns with congenital heart disease. $N$ Engl J Med. 2007;357:1928-38.

6. Mahle WT, Tavani F, Zimmerman RA, Nicolson SC, Galli KK, Gaynor JW, et al. An MRI study of neurological injury before and after congenital heart surgery. Circulation. 2002;106(12 Suppl 1):I109-14.
7. Beca J, Gunn JK, Coleman L, Hope A, Reed PW, Hunt RW, et al. New white matter brain injury after infant heart surgery is associated with diagnostic group and the use of circulatory arrest. Circulation. 2013;127:971-9.

8. Andropoulos DB, Hunter JV, Nelson DP, Stayer SA, Stark AR, McKenzie ED, et al. Brain immaturity is associated with brain injury before and after neonatal cardiac surgery with high-flow bypass and cerebral oxygenation monitoring. $J$ Thorac Cardiovasc Surg. 2009; 139:543-56.

9. Lynch JM, Buckley EM, Schwab PJ, McCarthy AL, Winters ME, Busch DR, et al. Time to surgery and preoperative cerebral hemodynamics predict postoperative white matter injury in neonates with hypoplastic left heart syndrome. $J$ Thorac Cardiovasc Surg. 2014;148:2181-8.

10. Petit CJ, Rome JJ, Wernovsky G, Mason SE, Shera DM, Nicolson SC, et al. Preoperative brain injury in transposition of the great arteries is associated with oxygenation and time to surgery, not balloon atrial septostomy. Circulation 2009;119:709-16. 